\title{
Validation of an experimental setup to study atmospheric heterogeneous ozonolysis of semi-volatile organic compounds
}

\author{
M. Pflieger, M. Goriaux, B. Temime-Roussel, S. Gligorovski, A. Monod, and H. Wortham \\ Laboratoire Chimie Provence, Equipe Instrumentation et Réactivité Atmosphérique, Marseille Université - CNRS, Case \\ courrier 29, 3 Place Victor Hugo, 13331 Marseille Cedex 3, France \\ Received: 17 September 2008 - Published in Atmos. Chem. Phys. Discuss.: 14 October 2008 \\ Revised: 9 February 2009 - Accepted: 6 March 2009 - Published: 24 March 2009
}

\begin{abstract}
There is currently a need for reliable experimental procedures to follow the heterogeneous processing simulating the atmospheric conditions. This work offers an alternative experimental device to study the behaviour of semi-volatile organic compounds (SVOC) that presumably exhibit extremely slow reactivity (e.g. pesticides) towards the atmospheric oxidants such as ozone and $\mathrm{OH}$. Naphthalene was chosen as a test compound since it was widely studied in the past and hence represents a good reference. Prior to ozone exposure, the gaseous naphthalene was adsorbed via gas-solid equilibrium on silica and XAD-4 particles. Then, the heterogeneous reaction of ozone with adsorbed naphthalene was investigated in specially designed flow tube reactors. After the reaction, the remaining naphthalene (adsorbed on particles surface) was extracted, filtered and analyzed by Gas Chromatography-Flame Ionization Detector (GC-FID). Thus, the kinetics results were obtained following the consumption of naphthalene. Using this procedure, the rate constants of heterogeneous ozonolysis of naphthalene $\left(k_{\mathrm{O}_{3} \text { silica }}=2.26( \pm 0.09) \times 10^{-17} \mathrm{~cm}^{3} \mathrm{molec}^{-1} \mathrm{~s}^{-1}\right.$ and $\left.k_{\mathrm{O}_{3} \mathrm{XAD}-4}=4.29( \pm 1.06) \times 10^{-19} \mathrm{~cm}^{3} \mathrm{molec}^{-1} \mathrm{~s}^{-1}\right)$ were determined for silica and XAD-4 particles, at $25^{\circ} \mathrm{C}$ and relative humidity $<0.7 \%$. The results show that the nature of the particles significantly affects the kinetics and that heterogeneous ozonolysis of naphthalene is faster than its homogeneous ozonolysis in the gas phase.
\end{abstract}

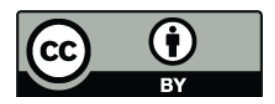

Correspondence to: M. Pflieger (maryline.pflieger@gmail.com)

\section{Introduction}

The increasing anthropogenic activities lead to an increase in the emissions of pollutants in the atmosphere. Among these pollutants, some semi-volatile organic compounds (SVOC) such as polycyclic aromatic hydrocarbons (PAHs) (Goriaux et al., 2006; Tasdemir et al., 2007) and pesticides (Chevreuil et al., 1996; Coupe et al., 2000; Hung et al., 2005; Scheyer et al., 2005; Sauret-Szczepanski et al., 2006) are commonly measured in the atmosphere in both urban regions and remote areas.

The adsorbed organic species may react with atmospheric oxidants colliding with the aerosol solid surfaces. These heterogeneous reactions control the atmospheric fate and lifetime of organic compounds adsorbed on aerosols. By analogy with the gaseous phase, it is assumed that, in the particulate phase, reactions with $\mathrm{OH}$ radicals, ozone and photolysis are major chemical transformation routes (Atkinson et al., 1999). Unfortunately, the absolute and relative importance of these various reactions is currently not well established.

Despite the importance of the heterogeneous reactivity to understand the behaviour of SVOC in the atmosphere, which are expected to exhibit slow reactivity, most of the works have focused on the reactions in the gaseous phase (Soderquist et al., 1975; Woodrow et al., 1978; Atkinson et al., 1984; Atkinson and Aschmann, 1986; Arey et al., 1989; Kwok et al., 1995; Bunce et al., 1997; Carter et al., 1997; Le Person et al., 2007). The reviews dealing with the atmospheric chemistry of Persistent Organic Compounds (POP) such as PAHs (Calvert et al., 2002) and pesticides (Atkinson et al., 1999) underline that the heterogeneous reactions of these compounds have received less attention than those acting in the gaseous phase. Therefore, atmospheric

Published by Copernicus Publications on behalf of the European Geosciences Union. 


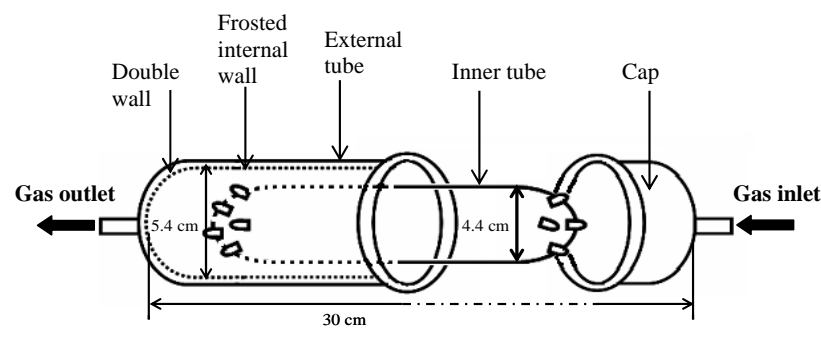

Fig. 1. The flow reactor.

heterogeneous reactivity is to be considered as an area of great uncertainty (Atkinson et al., 1999). The atmospheric lifetime based only on the mechanisms and the kinetic constants of the gaseous phase cannot explain the atmospheric behaviour of SVOC.

It is thus essential to investigate the heterogeneous reactivity of SVOC. To carry out such a study under controlled laboratory conditions, validated experimental procedures are required. Much of the data on heterogeneous reactions in the atmosphere, particularly the pioneering studies, were produced using Knudsen cells (Finlayson-Pitts and Pitts, 2000). Using this technique, the uptake coefficient of the gaseous reactant by the particles surfaces can be determined. However, this coefficient may not represent the true trapping of the gas due to the re-evaporation or the heterogeneous adsorption of organic compounds on the surface. Recently, Rudich et al. (2007) reviewed laboratory studies on the uptake of oxidants and also the evolution of particle-water interactions. Donaldson and Vaida (2006) published an interesting review on the influence of organic films at the air-aqueous interface. Some other techniques permit investigation of heterogeneous reactivity by determining the quantity of unreacted SVOC. Commonly, static aerosol chambers are used for studying slow heterogeneous reactions (Bossan et al., 1995; Palm and al., 1997) or flow tubes which contain the condensed phase of interest deposited on a solid support such as the reactor's walls (Kwamena et al., 2006), particles (Pöschl et al., 2001; Rudich, 2003) or filters (Perraudin et al., 2005; Esteve et al., 2004). Whichever experimental procedure is selected, the initial step generally consists in the coating protocol of particle with SVOC. Commonly, it consists in liquid-solid equilibrium of the compounds under study. Experimentally, these compounds are dissolved in an organic solvent together with the solid particles in suspension (Daisey et al., 1982; Wortham et al., 1993; Palm et al., 1999; Esteve et al., 2006; Perraudin et al., 2007a). This procedure makes it possible to coat a large quantity of SVOC on the particle but it is neither representative of the atmospheric phenomenon nor of atmospheric concentrations. A recent study (Perraudin et al., 2007b) showed that the concentration of particulate PAH may drastically influence the kinetics. This influence of the PAH concentrations could be induced by an experimental artefact because Alebic-Juretic et al. (1990) demonstrated that there is a significant discrepancy in the kinetics when the particles are covered with less or more than a monolayer of PAH. Since the sub-monolayer organic coverage is atmospherically relevant, it seems important to work with such monolayer of SVOC on aerosol particles. As a result, the adsorption procedure using liquid-solid equilibrium cannot be considered representative of atmospheric conditions since both the quantity of compounds adsorbed and the nature of the adsorption may be very different from those occurring in the atmosphere. Several recent works have used a gas-solid equilibrium in order to better mimic the atmospheric conditions (Pöschl et al., 2001; Kwamena et al., 2004; Gloaguen et al., 2006; Kwamena et al., 2007). In order to coat SVOC on particles simulating atmospheric conditions, we have developed an alternative experimental device using a gas-solid equilibrium of the SVOC as an adsorption method.

The purpose of this work is to describe this alternative experimental setup aimed at studying the heterogeneous reactivity of slowly reactive SVOC (e.g. pesticides). It has been tested on the heterogeneous ozonolysis of naphthalene adsorbed both on silica and XAD-4 particles used as surrogate solid supports. Naphthalene was chosen because it is known to react towards ozone, and because it is one of the most volatile SVOC (vapour pressure of $37 \mathrm{~Pa}$ at $25^{\circ} \mathrm{C}$; Lei et al., 2002). Therefore, this compound was an ideal candidate to test the possible experimental volatilization artefacts. Silica particles were chosen as a model solid carrier because $\mathrm{SiO}_{2}$ represents a significant part of tropospheric aerosol (AlebicJuretic et al., 1990; Usher, 2003b). To observe the influence of physico-chemical properties of particles on the heterogeneous reactivity, a second solid support (XAD-4), chemically different from $\mathrm{SiO}_{2}$ was tested. The XAD-4 resin was chosen because it is frequently used to trap SVOC and heterogeneous reactions are suspected to occur during sampling (Goriaux et al., 2006).

\section{Experimental}

The degradation studies were carried out in a flow reactor (30 cm long), which consists of two concentric tubes, for the larger one $5.4 \mathrm{~cm}$ internal diameter, and for the narrower one $4.4 \mathrm{~cm}$ external diameter. The two tubes were fitted inside each other leaving an annular space of $0.5 \mathrm{~cm}$ for the air flow (Fig. 1). The internal walls of the outer tube were fluoridric acid-etched that results in frosted-glass which facilitates the coating of particles, specifically on this part of the reactor. The outer tube was made up of a double wall which allows it to be thermostated. Gaseous naphthalene gently flowed through the reactor inducing an adsorption of naphthalene on the particles. Then, the adsorbed naphthalene was exposed, in the dark to controlled ozone concentrations. The degradation kinetics were determined by analysis of the remaining quantity of naphthalene after various times of ozone exposition. 


\subsection{Preliminary cleaning of the particles}

Silica particles are often used to simulate the atmospheric mineral aerosol (Palm et al., 1997, 1998, 1999; Perraudin et al., 2005, 2007a, b). They have the advantage of being homogeneous in diameter (diameter: $6-8 \mathrm{~nm}$ ) and to have a known specific surface $\left(260 \mathrm{~m}^{2} \mathrm{~g}^{-1}\right)$. Prior to use, the particles were heated at $600^{\circ} \mathrm{C}$ during $24 \mathrm{~h}$ in an oven and kept in a warm $\left(150^{\circ} \mathrm{C}\right)$ and dry atmosphere.

Amberlite XAD-4 resin, a styrene-divinylbenzene polymer, is known to be an efficient sorbent trap for volatile organic compounds such as PAH (Gundel et al., 1995; Temime et al., 2004). This resin was delicately crushed for $6 \mathrm{~h}$ in a planetary grinder (Retsch $\mathrm{GmbH}$ ) to obtain XAD-4 particles with a diameter of about $1 \mu \mathrm{m}$. Due to this treatment, the XAD-4 resin was contaminated by various compounds such as alkylated derivatives of benzene, styrene, naphthalene and biphenyl (Hunt and Pangaro, 1982). Therefore, several washing cycles by Soxhlet were necessary to obtain clean blanks (Temime at al., 2002). After each cycle, the liquid and solid phases were separated by ultracentrifugation for $5 \mathrm{~min}$ (Hettich Universal, 3200 revolutions $\min ^{-1}$ ). Finally, the XAD-4 was dried for $48 \mathrm{~h}$ at around $100^{\circ} \mathrm{C}$.

\subsection{Coating of particles on the wall of the reactor}

The operating procedure to coat the walls of the reactor was first described by Gundel et al. (1995), then, adapted by Temime et al. (2002) and finally applied to the current work. Prior to coating the frosted internal walls of the reactor with aerosols, $0.5 \mathrm{~g}$ of particles diluted in $50 \mathrm{~mL}$ of dichloromethane were ultrasonicated for $5 \mathrm{~min}$ (Branson 3510). The resulting slurry was applied to the walls of the reactor. Then, the excess slurry was removed and the reactor dried using a pure nitrogen flow. Several successive application/drying cycles were performed until no slurry remained. Using this procedure, the mean amount of particle losses was about $50 \%$. Thus, the quantity of particles coated on the wall of the reactor was about $0.25 \mathrm{~g}$.

\subsection{Generation of a constant flux of naphthalene}

The adsorption of naphthalene on the particles was performed by connecting the reactor to a permeation chamber described in detail elsewhere (Temime et al., 2002). Briefly, the permeation chamber delivered a gas standard diluted in pure nitrogen that was cleared of particles and gaseous organic compounds. The permeation chamber (Fig. 2a) was a glass vessel equipped with an inlet and an outlet, allowing a flow of pure nitrogen to pass through. It was placed in an oven thermostated at $40^{\circ} \mathrm{C}$ and contained a permeation cell which was a glass tube sealed with a PTFE semiporous membrane (Durieux PTFE membrane, pore: 10$15 \mu \mathrm{m}$, thickness: 0.0005 inches) and filled with naphthalene crystals. The membrane allowed the vapours produced

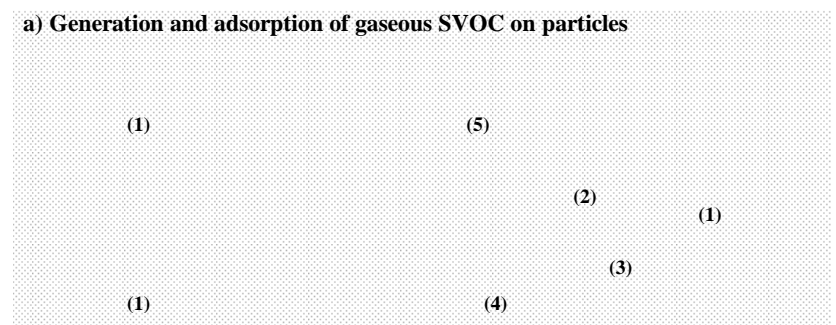

b) Heterogeneous ozonolysis in reactor $B$

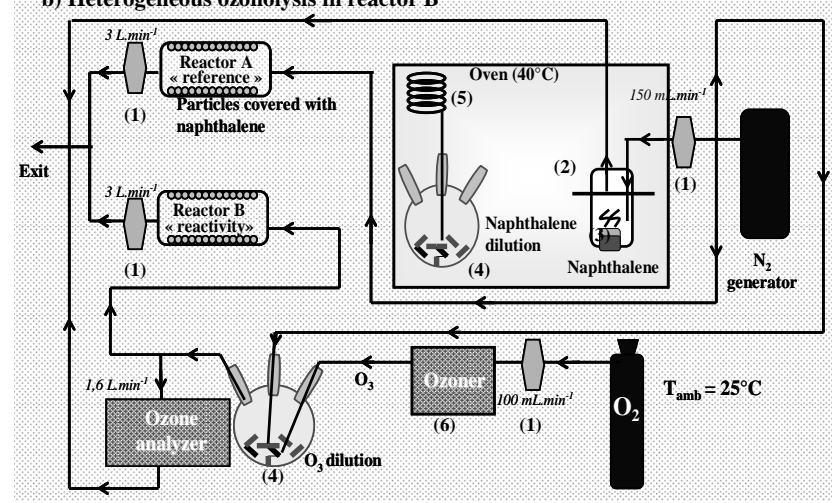

Fig. 2. Experimental set-up to study the heterogeneous ozonolysis of SVOC: (a) generation and adsorption of gaseous SVOC on particles, (b) heterogeneous ozonolysis in reactor B.

Legend:
(1) Mass flow controller
(2) Permeation chamber
(3) Permeation cell
(4) Dilution vessel
(5) Several meters of tubing
(6) Ozone generator

by the naphthalene sublimation to flow out the permeation cell in a steady manner. Therefore, a flow of naphthalene vapours diluted in pure nitrogen was obtained at the outlet of the permeation chamber. To obtain a stable concentration of naphthalene, two key parameters had to be accurately controlled: the flux of the carrier gas and the sublimation rate of naphthalene in the permeation cell.

The flux of the carrier gas, set at a flow rate of $150 \mathrm{~mL} \cdot \mathrm{min}^{-1}$, was controlled at the inlet of the permeation chamber by a mass flow controller $( \pm 1 \%$ full scale, range of the mass flow 0 to $500 \mathrm{~mL} \cdot \mathrm{min}^{-1}$ ). Under this condition, the volume of the permeation chamber was renewed every 2 min. The sublimation rate was highly sensitive to the temperature, thus the permeation chamber was thermostated at $40^{\circ} \mathrm{C} \pm 1^{\circ} \mathrm{C}$ and the entire experimental setup was placed in a room thermostated at $25 \pm 1^{\circ} \mathrm{C}$. In addition, to avoid a temperature fluctuation induced by the carrier gas, the latter was set at the working temperature by passing it through several meters of tubing circulating in the oven prior to go into the permeation chamber. Finally, the primary flux of gaseous naphthalene was diluted in an additional flux of pure nitrogen to obtain the required concentrations of naphthalene. This dilution occured in the thermostated oven $\left(40^{\circ} \mathrm{C}\right)$ to avoid naphthalene condensation. The diluted flow of naphthalene was set at $25 \pm 1^{\circ} \mathrm{C}$ corresponding to the temperature of the thermostated room. 
Table 1. Blank experiments: Ratio of the amount of naphthalene (Nap) adsorbed on silica particles coated on the internal surface of reactors $\mathrm{A}$ and $\mathrm{B}$, and their ratios.

\begin{tabular}{lllll}
\hline Experiment name & {$[\mathrm{Nap} \text { ads }]_{\text {reactor A }}(\mu \mathrm{g})$} & {$[\mathrm{Nap} \text { ads }]_{\text {reactor B }}(\mu \mathrm{g})$} & $\begin{array}{l}{[\mathrm{Nap} \text { ads }]_{\text {reactor A }}} \\
{[\mathrm{Napads}]_{\text {reactor B }}}\end{array}$ & Exposure time to $\mathrm{N}_{2}$ at 3 ${\mathrm{L} . \mathrm{min}^{-1}}^{-1}$ \\
\hline Blank 1 & 48.1 & 46.3 & 1.04 & 0 \\
Blank 2 & 49.6 & 45.4 & 1.09 & 0 \\
Blank 3 & 44.3 & 44.7 & 0.99 & 20 min \\
RSD of the concentration ratio: & & $5 \%$ & \\
\hline
\end{tabular}

\subsection{Adsorption of SVOC on particles}

The gaseous flux of naphthalene produced by the permeation device was divided into two equivalent fluxes passing through two similar reactors (reactor A and B) set up in parallel (Fig. 2a). The connections between the permeation device and the reactors were rigorously identical and as short as possible to avoid adsorption of gaseous naphthalene on the connexion tubes. The fluxes in the reactors were set at $3 \mathrm{~L} \cdot \mathrm{min}^{-1}$ controlled by two mass flow controllers $( \pm 1 \%$ full scale, range of the mass flow 0 to $10 \mathrm{~L}^{\mathrm{m}} \mathrm{min}^{-1}$ ) (Brooks Instrument, smart mass control) placed downstream of the reactors. Under these experimental conditions and with the design of the reactors, the Reynolds number $\left(\mathrm{N}_{\mathrm{Re}}\right)$ was less than 10. Thus, the flux was laminar and by diffusion the gaseous naphthalene reached the particles coated on the walls of the reactors. Moreover, the gas flow was too weak to extract the particles from the walls (Possanzini et al., 1983). This experimental procedure allows adsorption of semi-volatile organic compounds on particles, according to a gas-solid equilibrium, which simulates realistic atmospheric conditions. The adsorption step was carried out during a 3-h period to obtain a sufficient quantity of naphthalene for the analysis by GC-FID (see later Sect. 2.6). After the adsorption step, the reactors were disconnected from the permeation device prior to starting the reactivity step.

The amount of adsorbed naphthalene was well below the number of adsorption sites on the solid support (silica or XAD-4). Nevertheless, we cannot assure a uniform distribution of naphthalene on the aerosol surface. The latter statement could arguably be interpreted as multilayer naphthalene coverage on the few first centimeters of the length of the reactor. However, during the deposition process, a large part of gaseous naphthalene passed through the reactor. As a result, assuming a spherical geometry of the molecules, a sub-monolayer coverage could be asserted. Indeed, about $0.25 \mathrm{~g}$ of particles were coated on the reactor's wall which represents a total surface of $18125 \mathrm{~m}^{2}$ and $65 \mathrm{~m}^{2}$ for XAD-4 and silica particles, respectively. On the other hand, knowing both the surface of the naphthalene molecule ( $171 \AA^{2}$ following the assumption of spherical geometry) and the amount of naphthalene measured on the particles after the adsorption step (a maximum of $3.9 \times 10^{-7}$ mole and $4.1 \times 10^{-7}$ mole for XAD-4 and silica particles respectively), it was estimated that the percentage of aerosol surface coated with naphthalene was $0.002 \%$ and $0.6 \%$ for XAD- 4 and silica particles, respectively.

\subsection{Heterogeneous ozonolysis}

The two reactors were assumed to be equivalent. This hypothesis was verified by carrying out blank experiments (with naphthalene but without ozone) to ensure that the initial amount of naphthalene was identical in both reactors, using silica as a solid support. The results, presented in Table 1 , show that the initial amount of naphthalene was almost identical in the two reactors taking into account a relative standard deviation of $3 \%$ for the analytical method. Moreover, the gaseous flow passing through the reactors did not significantly influence the quantity of naphthalene adsorbed on the solid surface (Table 1). Therefore, in the present study, one of the reactors was used as a reference to determine the initial concentration of naphthalene adsorbed on the particles (Reactor A) while the other one was used to carry out reactivity experiments (Reactor B). An ozone flux was obtained by submitting a pure oxygen flux to an electrical discharge (Fig. 2b) and it was then diluted with a pure nitrogen flow to obtain concentrations ranging from $0.2 \mathrm{ppm}$ to $4.3 \mathrm{ppm}$. The exact concentrations of ozone, which enter into reactor $\mathrm{B}$, were measured on-line using a commercial ozone analyzer (O3 41M, Environnement S.A). The ozone concentration was kept constant throughout the experiment. Due to our experimental conditions (flow tube in which the gaseous phase was continuously renewed), ozone was kept in excess compared to naphthalene during all the experiments. During a test experiment, the ozone monitor was connected alternatively at the inlet and the outlet of the reactor, and no significant variation of ozone concentrations was observed. Moreover, the diffusion coefficient of ozone in nitrogen is $0.148 \mathrm{~cm}^{2} \cdot \mathrm{s}^{-1}$ (at $1 \mathrm{~atm}$ and $298 \mathrm{~K}$ ) (Fuller et al., 1966) which corresponds to a maximum diffusion time of $1.7 \mathrm{~s}$ in the reactor. This diffusion time is lower than the resident time $(7.5 \mathrm{~s})$ of ozone in the reactor and much lower than the exposure times (12-204 min). As a result, the diffusion was negligible. At the end of the experiments, a flux of nitrogen-free ozone was led into reactor B in order to eliminate the remaining ozone and to stop the reaction. 


\subsection{Extraction, filtration and analysis}

After each experiment, naphthalene was extracted from the particles in $2 \times 25 \mathrm{~mL}$ of dichloromethane by shaking the reactor manually (2 times during $3 \mathrm{~min}$ each). Prior to the extraction, the internal tube was removed, in order to specifically extract the naphthalene adsorbed on particles on the internal wall of the external tube. A sample $(10 \mathrm{~mL})$ of each extract was filtered on a PTFE filtration cartridge (Iso-Disc Filters PTFE 25-4, $25 \mathrm{~mm} \times 0.45 \mu \mathrm{m}$, Supelco, pre-conditioned with $5 \times 10 \mathrm{~mL}$ of dichloromethane) in order to eliminate the particles prior to analysis. The filtrate was immediately and quantitatively analysed using gas chromatography (Trace GC ULTRA, Thermo Electron Corporation) on a non-polar capillary column (CP-SIL8 CB; $30 \mathrm{~m} \times 0.32 \mathrm{~mm} \mathrm{df}=0.25 \mu \mathrm{m} ; 5 \%$ diphenyle copolymere and $95 \%$ dimethylpolysiloxane; Varian). The chromatograph was equipped with a Flame Ionisation Detector (FID) and a large volume injector to allow the carrying out of a temperature program to evaporate the solvent (PTV-LVI). The injector contained an inert liner filled with silica wool (Silcosteel deactivated liner with deactivated silica wool; $\mathrm{ID}=2 \mathrm{~mm} ; \mathrm{OD}=2.75 \mathrm{~mm} ; 1=120 \mathrm{~mm}$, $\mathrm{v}=0.38 \mathrm{~mL}$; Thermo Electron Corporation) which retain the SVOC such as naphthalene during the evaporation process. Large volume injections in the PTV-LVI (up to $150 \mu \mathrm{L}$ ) permitted to avoid the carrying out of a pre-concentration step which would have decreased the precision of the analytical procedure. The volume injected was $80 \mu \mathrm{L}(100 \mu \mathrm{L}$ syringe; needle $1=50 \mathrm{~mm}$ and gauge 23 ; Thermo Electron Corporation) and the sample quantification was carried out using external calibration. The analytic parameters are presented in Fig. 3. The performance of the analytical procedure of naphthalene using PTV-LVI-GC-FID were the following: Relative Standard Deviation $(\mathrm{RSD})=3 \%$, Quantification Limit $(\mathrm{QL})=$ Detection Limit $(\mathrm{DL})=6.4 \times 10^{-4} \mu \mathrm{g}$, linearity range $=\left[5.6 \times 10^{2} ; 6.4 \times 10^{-4}\right] \mu \mathrm{g}$.

\subsection{Reagents}

The reagents used for the experiments were dichloromethane (>99.9\%, Fluka, Sigma-Aldrich Chemical), naphthalene (Scintillation grade 99+\%, Acros organics), silica particles $(\geq 99.8 \%$, AEROSIL R812, specific surface: $260 \mathrm{~m}^{2} \cdot \mathrm{g}^{-1}$, diameter: $6-8 \mathrm{~nm}$ ), XAD-4 particles (surface area: $72500 \mathrm{~m}^{2} \cdot \mathrm{g}^{-1}$, porosity: $50 \AA$, diameter: $\left.1 \mu \mathrm{m}\right)$, oxygen (99 999\%, Linde Gas, France), nitrogen (99 999\%, Linde Gas, France, and Nitrogen generator $\mathrm{N}_{2}$ LCMS, Claind).

\section{Kinetics}

The kinetics of heterogeneous ozonolysis of naphthalene were studied by determining the quantity of non-reacted naphthalene, i.e. the quantity of naphthalene remaining in reactor $\mathrm{B}$ after exposure to ozone. Two different heteroge-

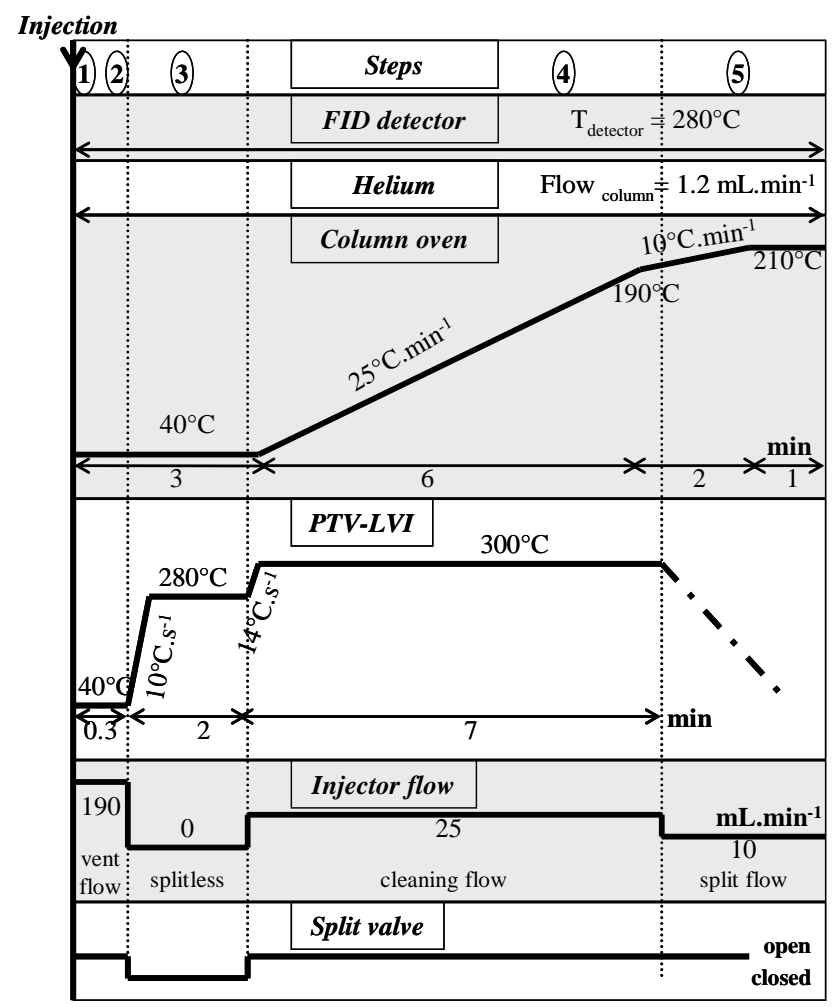

Fig. 3. Parameters of the analysis line

Step 1: Injection of the sample.

Step 2: Evaporation and elimination of the solvent.

Step 3: Transfer of target compounds from the injector to the column head.

Step 4: Cleaning of the injector, compounds separation and detection.

Step 5: End of the cycle for PTV-LVI and re-initialisation.

neous mechanisms can occur: the Langmuir-Rideal and the Langmuir-Hinshelwood patterns.

\subsection{Langmuir-Rideal pattern}

According to the Langmuir-Rideal pattern, the heterogeneous reaction between naphthalene adsorbed on particles $\left(\mathrm{Nap}_{\mathrm{ads}}\right)$ and gaseous ozone $\left(\mathrm{O}_{3 \mathrm{~g}}\right)$ passing through reactor $\mathrm{B}$, is described by Reaction ( $\mathrm{R} 1)$.

Napads $+\mathrm{O}_{3 \mathrm{~g}} \rightarrow$ Products

The kinetic expression of Eq. (1) is given by Reaction (R1).

$\frac{d\left[\mathrm{Nap}_{\mathrm{ads}}\right]}{d t}=-k \times\left[\mathrm{O}_{3 \mathrm{~g}}\right] \times\left[\mathrm{Nap}_{\mathrm{ads}}\right]$

where $k$ is the second order rate constant of the reaction.

Under our experimental conditions, ozone was in excess compared to the adsorbed naphthalene and continuously 
Table 2. Results of the heterogeneous ozonolysis of naphthalene (Nap) adsorbed on silica and XAD-4 particles.

\begin{tabular}{|c|c|c|c|c|c|}
\hline $\begin{array}{l}\text { Experiment } \\
\text { name }\end{array}$ & $\begin{array}{l}\text { Quantity of Nap } \\
(\mu \mathrm{g}) \text { at time } 0 \\
(\text { in reactor } \mathrm{A})^{\mathrm{a}}\end{array}$ & $\begin{array}{l}\mathrm{O}_{3} \text { exposure } \\
\text { time } t(\mathrm{~min})\end{array}$ & {$\left[\mathrm{O}_{3}\right]_{\text {median }}^{\mathrm{b}}(\mathrm{ppm})$} & $\frac{[\text { Napads }]_{0}}{[\text { Napads }]_{t}}$ & $\frac{1}{t} \times \ln \left(\frac{\left[\mathrm{Nap}_{\mathrm{ads}}\right]_{0}}{\left[\mathrm{Napads}_{t}\right]_{t}}\right)\left(\mathrm{s}^{-1}\right)$ \\
\hline Silica 1 & 44.9 & 12 & $3.44 \pm 0.17$ & 5.1 & $2.3( \pm 0.2) \times 10^{-3}$ \\
\hline Silica 2 & 46.7 & 12.25 & $3.32 \pm 0.17$ & 5.0 & $2.2( \pm 0.2) \times 10^{-3}$ \\
\hline Silica 3 & 46.5 & 17 & $2.40 \pm 0.12$ & 5.0 & $1.6( \pm 0.1) \times 10^{-3}$ \\
\hline Silica 4 & 46.0 & 17 & $1.80 \pm 0.09$ & 3.6 & $1.2( \pm 0.1) \times 10^{-3}$ \\
\hline Silica 5 & 46.7 & 22.5 & $0.95 \pm 0.05$ & 3.0 & $8.2( \pm 0.5) \times 10^{-4}$ \\
\hline Silica 6 & 47.1 & 17.25 & $0.61 \pm 0.03$ & 1.9 & $6.4( \pm 0.7) \times 10^{-4}$ \\
\hline Silica 7 & 47.8 & 32 & $0.84 \pm 0.04$ & 3.5 & $6.5( \pm 0.4) \times 10^{-4}$ \\
\hline Silica 8 & 50.3 & 15.75 & $4.27 \pm 0.21$ & 10.8 & $2.5( \pm 0.3) \times 10^{-3}$ \\
\hline Resin 1 & 54.5 & 193 & $2.41 \pm 0.12$ & 1.4 & $2.7( \pm 0.4) \times 10^{-5}$ \\
\hline Resin 2 & 59.2 & 204 & $4.08 \pm 0.20$ & 1.9 & $5.4( \pm 0.5) \times 10^{-5}$ \\
\hline Resin 3 & 56.2 & 187 & $0.97 \pm 0.05$ & 1.3 & $2.6( \pm 0.4) \times 10^{-5}$ \\
\hline Resin 4 & 53.2 & 193 & $0.22 \pm 0.01$ & 1.1 & $8.0( \pm 0.4) \times 10^{-5}$ \\
\hline
\end{tabular}

${ }^{a}$ Reactor $A=$ reference reactor. ${ }^{b}$ Median ozone concentration of ozone measured during the ozonolysis experiments.

flowed through reactor B. We can thus assume a pseudo-first order kinetic (Reaction R2).

$\frac{d\left[\mathrm{Nap}_{\mathrm{ads}}\right]}{\left[\mathrm{Nap}_{\mathrm{ads}}\right]}=-k_{\mathrm{exp}}^{\prime} \times d t$

where $k_{\exp }^{\prime}=k\left[\mathrm{O}_{3 \mathrm{~g}}\right]$ is the experimental pseudo-first order rate coefficient. The integration of Reaction (R2) gives Reaction (R3):

$$
\frac{1}{t} \times \ln \left(\frac{\left[\mathrm{Nap}_{\mathrm{ads}}\right]_{0}}{\left[\mathrm{Nap} \mathrm{pads}_{t}\right.}\right)=k \times\left[\mathrm{O}_{3 \mathrm{~g}}\right]=k_{\mathrm{exp}}^{\prime}
$$

In the Langmuir-Rideal patern, plotting $\frac{1}{t} \times \ln \left(\frac{\left[\text { Pestads }_{\text {ad }}\right]_{0}}{\left[\text { Pest }_{\text {ads }}\right]_{t}}\right)=$ $k_{\text {exp }}^{\prime}$ as a function of $\left[\mathrm{O}_{3 \mathrm{~g}}\right]$ gives a linear plot, with a slope of $k$.

\subsection{Langmuir-Hinshelwood pattern}

Pöschl et al. (2001) suggested that the heterogeneous reactions between a gaseous oxidant and an organic compound adsorbed on a solid support can be attributed to the Langmuir-Hinshelwood reaction pattern. According to this mechanism, the organic species are adsorbed on the solid surface and the oxidant species are in equilibrium between the gaseous and solid phases. A reaction can occur only when the gaseous phase species are adsorbed on the surface. Nevertheless, only a limited number of adsorption sites are available for the oxidant gaseous species and at some gaseous phase concentration, saturation of the surface occurs (Kwamena et al., 2006). As a result, the rate of the reaction becomes independent of the oxidant gaseous concentration.
The Langmuir-Hinshelwood reaction mechanism can be described using the Reaction (R4).

$\frac{k^{\mathrm{II}}[\mathrm{SS}] K_{\mathrm{O}_{3}}\left[\mathrm{O}_{3 \mathrm{~g}}\right]}{1+K_{\mathrm{O}_{3}}\left[\mathrm{O}_{3 \mathrm{~g}}\right]}=k_{\mathrm{obs}}^{\mathrm{I}}$

where $k^{\mathrm{II}}$ is the second order surface rate coefficient, $[\mathrm{SS}]$ is the number of adsorption sites for ozone, $K_{\mathrm{O}_{3}}$ is the ozone gas-surface equilibrium constant and $\left[\mathrm{O}_{3 \mathrm{~g}}\right]$ is the gaseous ozone concentration. Plotting $k_{\mathrm{obs}}^{\mathrm{I}}$ versus $\left[\mathrm{O}_{3 \mathrm{~g}}\right]$ gives a nonlinear plot. Moreover, $k^{\mathrm{II}}$ multiplied by [SS] can be approximated as the maximum rate coefficient $k_{\max }^{\mathrm{I}}$ experimentally obtained at high ozone concentration (Kahan et al., 2006; Kwamena et al., 2007). As a result, equation (R4) can be modified to yield equation (R5).

$\frac{k_{\max }^{\mathrm{I}} K_{\mathrm{O}_{3}}\left[\mathrm{O}_{3 \mathrm{~g}}\right]}{1+K_{\mathrm{O}_{3}}\left[\mathrm{O}_{3 \mathrm{~g}}\right]}=k_{\mathrm{obs}}^{\mathrm{I}}$

The parameters $K_{\mathrm{O}_{3}}$ and $k_{\max }^{\mathrm{I}}$ can be obtained by fitting the experimental results $k_{\mathrm{obs}}^{\mathrm{I}}$ as function of $\left[\mathrm{O}_{3 \mathrm{~g}}\right]$ using a nonlinear least-squares fit of Eq. (5) based on an appropriate algorithm.

\section{Results and discussion}

Twelve experiments of heterogeneous ozonolysis of naphthalene were carried out: eight experiments with a solid support of silica (Experiments Silica 1 to Silica 8); and four experiments with solid support of XAD-4 (Experiments Resin 1 to Resin 4). The results (Table 2) show that the amounts of naphthalene adsorbed on the reference reactor (reactor A) 
were equivalent in the various experiments carried out using the same solid support independently of the duration of the experiments. These results clearly demonstrate that the adsorption procedure was reproducible and the volatilization phenomenon was negligible under the experimental conditions (without ozone) applied in this study.

\subsection{Treatment of the experimental data using the Langmuir-Rideal pattern}

The Langmuir-Rideal mechanism involves only one reactant adsorbed on the surface prior to the reaction. The atmospheric oxidant such as ozone then collides with the surface adsorbed naphthalene and further reacts.

For each experiment, the remaining concentration of naphthalene, $\left[\mathrm{Nap}_{\mathrm{ads}}\right]_{t}$, following the exposure to ozone was compared to the concentration, $\left[\mathrm{Nap}_{\mathrm{ads}}\right]_{0}$, in the reference reactor $\left(R_{A}\right)$. The value of $k_{\exp }^{\prime}$ was determined according to Reaction (R3) where $t$ is the time of ozone exposure (Table 2).

The experiments were carried out at median ozone concentrations ranging from $0.2 \mathrm{ppm}$ to $4.3 \mathrm{ppm}$. These concentrations were higher than those usually observed in the atmosphere but were essential in obtaining a significant degradation of naphthalene during an experiment of 12 to $204 \mathrm{~min}$ (Table 2).

Due to the instability of the ozone generator, the concentrations of ozone fluctuated during a few minutes. However, the instantaneous concentrations of ozone were not relevant for the kinetic experiments. Nevertheless, because the ozone concentrations were not well described by a Gaussian, the median ozone concentrations were used instead of the usual mean ozone concentrations. The uncertainty of the median concentration was given by the ozone analyser $(5 \%)$.

Plotting $\frac{1}{t} \times \ln \left(\frac{\left[\text { Pest }_{\text {ads }}\right]_{0}}{\left[\text { Pestass }_{t}\right.}\right)=k_{\exp }^{\prime}$ as a function of ozone concentrations was fit with a linear regression $\left(R^{2}=0.99\right.$ and 0.94 , respectively for silica and XAD4 particles) (Fig. 4). According to Reaction (R3), the slope of the linear regressions gave $k_{\mathrm{O}_{3} \text { silica }}=2.26$ $( \pm 0.09) \times 10^{-17} \mathrm{~cm}^{3} \cdot \mathrm{molec}^{-1} \cdot \mathrm{s}^{-1} \quad$ (at $25^{\circ} \mathrm{C}$ ) and

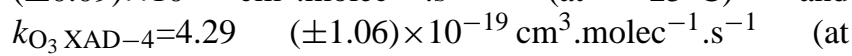
$25^{\circ} \mathrm{C}$ and $\mathrm{HR}<0.7 \%$ ) for solid supports of silica and XAD-4, respectively.

The experiments performed by Michel et al. (2003) and Usher et al. (2003a) have shown that ozone reacts with solid surfaces such as silica or kaolinite. Thus, we could assume that these reactions may modify the physico-chemical properties of the solid surface and change the gas-solid equilibrium of the organic compounds. The latter implies that the interactions between ozone and the silica support can arguably induce the volatilization of organic compounds (naphthalene) in reactor B. Such a behaviour could possibly explain why the regression lines in Fig. 4 do not pass through the origin.

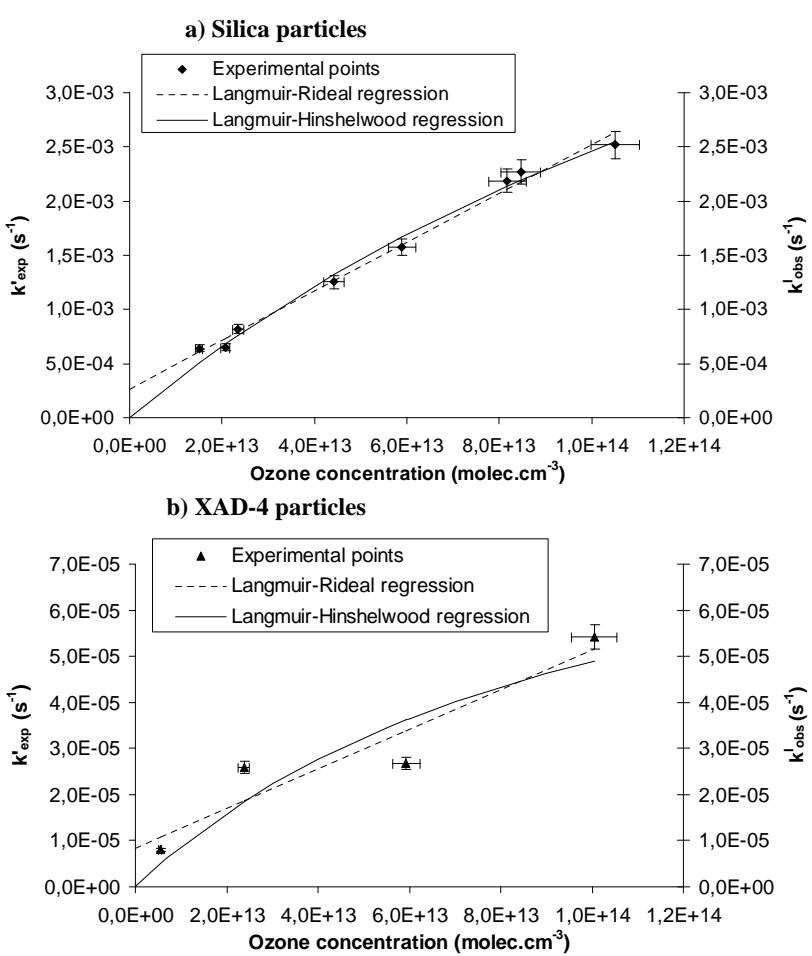

Fig. 4. Graph of the experimental apparent rate constant $k_{\exp }^{\prime}\left(\mathrm{s}^{-1}\right)$ and $k_{\text {obs }}^{\mathrm{I}}\left(\mathrm{s}^{-1}\right)$ versus ozone concentration $\left(\text { molec. } \mathrm{cm}^{-3}\right)^{\mathrm{a}}$ of naphthalene adsorbed (a) on silica particles, and (b) on XAD-4 particles.

a The vertical errors bars: RSD on the pseudo first order constant $k_{\exp }^{\prime}$ integrating both the RSD on the ratio reactor $\mathrm{A} /$ reactor $\mathrm{B}$ and the duration of the experiment under study. Using the RSD on $k_{\exp }^{\prime}$ and the scattering of the experimental data, the error on the slope $k$ was calculated using the algorithm available in the Origin 6.0 software.

The obtained results show a great influence of the nature of the particles. The degradation of naphthalene is faster (almost 50 times) when adsorbed on silica surface than on XAD-4 particles (Table 4). Note that XAD-4 particles are not of atmospheric interest, whereas silica particles may be of great atmospheric importance (Usher et al., 2003b). Because XAD-4 particles are often used as very efficient means for trapping the atmospheric PAH (Temime et al., 2004), our results show that it is important to consider the heterogeneous ozonolysis of PAH when adsorbed on XAD-4 surface, particularly for field measurements.

\subsection{Treatment of the experimental data using the Langmuir-Hinshelwood pattern}

The data in Fig. 4 were fit using a nonlinear least-squares fit of equation (R5) based on the Levenberg-Marguardt algorithm in the Origin 6.0 data analysis software package. The fitting parameters gave $k_{\max }^{I} \mathrm{XAD}-4=1.0( \pm 0.9) \times 10^{-4} \mathrm{~s}^{-1}$ and $k_{\max \text { silica }}^{I}=7.8( \pm 1.7) \times 10^{-3} \mathrm{~s}^{-1}$ and $K_{\mathrm{O}_{3} \mathrm{XAD}-4}=9.6$ 
Table 3. Rate constants for the homogeneous and heterogeneous ozonolysis of naphthalene and its resulting lifetimes. For the heterogeneous reactivity, both silica and XAD-4 particles were tested, and for both particles, Langmuir-Rideal (LR) and Langmuir-Hinshelwood models (LH) are considered.

\begin{tabular}{|c|c|c|c|c|c|c|}
\hline Reactions & Lifetimes $^{c}$ & $\begin{array}{l}k \\
\left(\times 10^{-19} \mathrm{~cm}^{3} \cdot \operatorname{molec}^{-1} \cdot \mathrm{s}^{-1}\right)\end{array}$ & $\begin{array}{l}k_{\text {obs }}^{\mathrm{I} c} \\
\left(\mathrm{~s}^{-1}\right) \\
(298 \mathrm{~K})\end{array}$ & $\begin{array}{l}k_{\max }^{\mathrm{I}} \\
\left(\times 10^{-5}\right. \\
\left.\mathrm{s}^{-1}\right) \\
(298 \mathrm{~K})\end{array}$ & $\begin{array}{l}K_{\mathrm{O}_{3}} \\
\left(\times 10^{-15} \mathrm{~cm}^{3}\right) \\
(298 \mathrm{~K})\end{array}$ & References \\
\hline $\begin{array}{l}\mathrm{Nap}_{g}+\mathrm{O}_{3 \mathrm{~g}} \rightarrow \mathrm{P} \\
\mathrm{Gas}\end{array}$ & $\begin{array}{l}>80 \text { days }^{\mathrm{a}} \\
>82 \text { days }^{\mathrm{a}} \\
>55 \text { days }^{\mathrm{a}}\end{array}$ & $\begin{array}{l}- \\
<2.01(294 \mathrm{~K}) \\
<3.01(295 \mathrm{~K})\end{array}$ & - & - & - & $\begin{array}{l}\text { Zielinska, } 2005 \\
\text { Atkinson et al., } 1984 \\
\text { Atkinson et al., } 1986\end{array}$ \\
\hline \multirow[t]{2}{*}{$\begin{array}{l}\mathrm{Nap}_{\text {ads }}+\mathrm{O}_{3 \mathrm{~g}} \rightarrow \mathrm{P} \\
\text { XAD-4 } \\
\text { LR }\end{array}$} & 16 days $^{b}$ & $10 \pm 2(298 \mathrm{~K})$ & - & - & - & Goriaux, 2006 \\
\hline & 38 days $^{b}$ & $4.29 \pm 1.06(298 \mathrm{~K})$ & - & - & - & This work \\
\hline $\begin{array}{l}\text { Napads }+\mathrm{O}_{3} \text { ads } \rightarrow \mathrm{P} \\
\text { XAD-4 } \\
\text { LH }\end{array}$ & 17 days $^{b}$ & - & $6.6810^{-7}$ & $0.1 \pm 0.9$ & $9.6 \pm 14$ & This work \\
\hline $\begin{array}{l}\mathrm{Nap}_{\text {ads }}+\mathrm{O}_{3 \mathrm{~g}} \rightarrow \mathrm{P} \\
\text { Silica } \\
\text { LR }\end{array}$ & $17 \mathrm{~h}$ & $226 \pm 9(298 \mathrm{~K})$ & - & - & - & This work \\
\hline $\begin{array}{l}\mathrm{Nap}_{\text {ads }}+\mathrm{O}_{3} \text { ads } \rightarrow \mathrm{P} \\
\text { Silica } \\
\text { LH }\end{array}$ & $11 \mathrm{~h}$ & - & $2.5310^{-5}$ & $7.8 \pm 1.7$ & $4.6 \pm 1.3$ & This work \\
\hline
\end{tabular}

a Lifetimes reported by Zielinska (2005) and calculated according to the rate constants determined by Atkinson et al. (1984) and Atkinson et al. (1986), respectively. ${ }^{b}$ The lifetime of heterogeneous ozonolysis of naphthalene adsorbed on XAD-4 has no atmospheric implication (XAD-4 do not represent atmospheric particles), however, the obtained values demonstrate a possible artefact reaction during sampling.

c for $\left[\mathrm{O}_{3}\right]=28.6 \mathrm{ppb}$.

$( \pm 14) \times 10^{-15} \mathrm{~cm}^{3}$ and $K_{\mathrm{O}_{3} \text { silica }}=4.6 \quad( \pm 1.3) \times 10^{-15} \mathrm{~cm}^{3}$ with $R^{2}=0.83$ and 0.99 for XAD-4 and silica particles, respectively (Table 3 ). The errors for $k_{\max }^{\mathrm{I}}$ and $K_{\mathrm{O}_{3}}$ were obtained from the statistical error of the nonlinear least-squares fit.

Comparing $\mathrm{K}_{\mathrm{O}_{3}}$ values for different substrates, Kwamena et al. (2004) showed that the adsorption of ozone is favoured on non-polar surfaces: $K_{\mathrm{O}_{3}}$ values range from less than $1.2 .10^{-16} \mathrm{~cm}^{3}$ (for hydrophilic sodium chloride aerosols) up to $2.8 .10^{-13} \mathrm{~cm}^{3}$ (for hydrophobic soot aerosols) (Kwamena et al., 2004). The $K_{\mathrm{O}_{3}}$ values obtained in the present work are comprised of these two extremes, in good agreement with the polarities of silica and XAD-4 particles which include sodium chloride and soot particles. Furthermore, our value for $K_{\mathrm{O}_{3} \text { silica }}\left(4.6( \pm 1.3) \times 10^{-15} \mathrm{~cm}^{3}\right)$ is similar to the value for $K_{\mathrm{O}_{3}}$ non activated silica gel $\left(9.5 .10^{-15} \mathrm{~cm}^{3}\right)$ reported by Kwamena et al. (2004).

According to the Langmuir-Hinshelwood mechanism, the reactivity occurs between adsorbed naphthalene and adsorbed ozone at the aerosol surface. When all surface sites are occupied, the reaction rate becomes independent of the gaseous ozone concentration. Under our experimental conditions, the saturation of the surface by ozone was not reached. However, an extended range of ozone concentrations would not represent the realistic atmospheric condi- tions. The observed rate constants for $28.6 \mathrm{ppb}$ of ozone are $k_{\mathrm{obs}}^{\mathrm{I}}=6.68 \times 10^{-7} \mathrm{~s}^{-1}$ and $k_{\mathrm{obs}}^{\mathrm{I}}=2.53 \times 10^{-5} \mathrm{~s}^{-1}$ for XAD-4 and silica particles, respectively. Thus, as for the LangmuirRideal treatment, the two substrates under study drastically affect the reactivity of naphthalene with ozone.

Goriaux (2006) demonstrated that, for ozone concentrations comprised between $64 \mathrm{ppb}$ and $5 \mathrm{ppm}$, the rate constants of the same heterogeneous reaction (ozone with naphthalene adsorbed on XAD-4 particles) exhibited a LangmuirRideal behaviour, and their rate constant is similar to the one obtained in the present study (Table 3 ).

The above discussion shows that our experimental data can exhibit both a Langmuir-Rideal and a LangmuirHinshelwood behaviour, and it is not possible to distinguish between the two mechanisms.

\subsection{Atmospheric implications}

The rate constants as emerged from this study were used to calculate the atmospheric lifetimes $(\tau)$ of naphthalene according to Reaction (R6) (Finlayson-Pitts and Pitts, 2000),

$\tau=\frac{1}{k\left[\mathrm{O}_{3}\right]}$ 
and according to Reaction (R7) (for the LangmuirHinshelwood pattern),

$\tau=\frac{1}{k_{\mathrm{obs}}^{I}}$

and assuming, (i) that the heterogeneous reaction of naphthalene with ozone is the only degradation process occurring in the atmosphere, and (ii) an ozone concentration of $28.6 \mathrm{ppb}$. The latter concentration allows for a comparison between our results and those of Zielinska et al. (2005) (Table 3).

Atmospheric lifetime of naphthalene, due to the reaction with ozone in the gas phase, has been calculated to be higher than 80 days (Zielinska, 2005). In comparison, based on our results, the heterogeneous lifetime of naphthalene, is much smaller, independent of both the solid substrate (XAD-4 or silica) and the reaction mechanism (Table 3 ). These results corroborate a previous study carried out on thirteen $\mathrm{PAH}$ adsorbed on silica and graphite particles (Perraudin et al., 2007b).

Perraudin et al. (2005) and (2007b) have studied the ozonolysis of PAHs (excluding naphthalene) adsorbed on graphite and silica. They observed different reactivities depending on the substrate. The same phenomenon was monitored in the current study. The authors suggested a possible influence of both the chemical composition of the aerosols and their physical structure (specific surface, pore size). It was assumed that these physical parameters could modify the surface rate coverage and thus the quantity available for reaction (Perraudin et al., 2007b; Alebic-Juretic et al., 1990). Using our experimental protocol, the amount of PAH initially adsorbed on the solid support was controlled, thus, it was possible to assert that both the amount of naphthalene was similar on the two solid surfaces and the experiments were carried out with naphthalene concentrations far below a monolayer. As a result, the amount of naphthalene available for reaction was similar for the two solid supports under study (Table 2) which invalidates the hypothesis by Perraudin et al. (2007b) and Alebic-Juretic et al. (1990). Two other hypotheses could be put forward to explain this phenomenon:

1. The difference in the chemical composition of the solid support could modify the nature of the Van der Vaals interactions occurring between naphthalene and the solid surface which in turn could modify the activation energy of the PAH under study.

2. The difference in the pore sizes of the solid supports under study could more or less efficiently protect the PAH depending on the ability of ozone to penetrate into the pores.

Unfortunately, the current study does not permit further validation and credibility of these hypotheses.

\section{Conclusions}

An experimental setup was developed to study the heterogeneous reactivity of SVOC with ozone. It consisted in generating a constant gaseous flow of SVOC which was split between two reactors. The internal walls of each reactor were covered with a homogeneous surface of particles. Thus, according to a solid-gas equilibrium, a part of the gaseous SVOC was adsorbed on the solid surface simulating the adsorption-desorption phenomenon occurring in the atmosphere. The compounds adsorbed on particles were exposed to ozone and the kinetics of ozonolysis were calculated by comparing adsorbed SVOC concentrations exposed to an $\mathrm{O}_{3}+\mathrm{N}_{2}$ flow to adsorbed SVOC concentrations exposed to a $\mathrm{N}_{2}$ flow. Naphthalene was chosen as a proxy to simulate atmospheric PAH because of its high reactivity towards ozone and due to its high volatility which facilitated its production into the gaseous phase and allowed us to test the experimental artefacts of volatilization under the worst conditions.

The heterogeneous reactivity of naphthalene adsorbed on two different kinds of particles (silica and XAD-4) have shown that the degradation rate was significantly influenced by the particles (chemical and/or physical composition). Moreover, our results demonstrated that the heterogeneous reactions are faster compared to those found in the gaseous phase. Hence, it can be concluded that degradation of naphthalene adsorbed on solid carriers under ozone processing could be an important sink for this compound in the atmosphere.

Because of the important degradation rate of PAH adsorbed on particles, a realistic estimation of their atmospheric lifetime must take into account both the homogeneous and heterogeneous reactivities. Satisfying estimates of these lifetimes will provide a better knowledge of the atmospheric behaviour of these compounds.

Finally, this work cannot provide a clear picture of the mechanism of the reactivity (Langmuir-Rideal or LangmuirHinshelwood patern). However, the proposed alternative approach can be very useful to elucidate the heterogeneous reactivity of organic compounds which react very slowly towards ozone (e.g. pesticides) under well-controlled laboratory conditions.

Acknowledgements. This work is financed by the French Environmental Ministry (Primequal 2 program) and ADEME (Agence de l'Environnement et de la Maîtrise de l'Energie).

Edited by: V. F. McNeill 


\section{References}

Alebic-Juretic, A., Cvitas, T., and Klasinc, L.: Heterogeneous polycyclic aromatic hydrocarbon degradation with ozone on silica gel carrier, Environ. Sci. Technol., 24, 62-66, 1990.

Arey, J., Zielinska, B., Atkinson, R., and Aschmann, S. M.: Nitroarene products from the gas-phase reactions of volatile polycyclic aromatic hydrocarbons with the $\mathrm{OH}$ radical and $\mathrm{N}_{2} \mathrm{O}_{5}$, Int. J. Chem. Kinet., 21, 775-799, 1989.

Atkinson, R., Aschmann, S. M., and Pitts Jr., J. N.: Kinetics of the reactions of naphthalene and biphenyl with hydroxyl radicals and with ozone at $294 \pm 1 \mathrm{~K}$, Environ. Sci. Technol., 18, 110-113, 1984.

Atkinson, R. and Aschmann, S. M.: Kinetics of the reactions of naphthalene, 2 methylnaphthalene, and 2, 3dimethylnaphthalene with hydroxyl radicals and with ozone at 295 \pm 1 K, Int. J. Chem. Kinet., 18, 569-573, 1986.

Atkinson, R., Guicherit, R., Hites, R. A., Palm, W. U., Seiber, J. N., and De Voogt, P.: Transformations of pesticides in the atmosphere: a state of the art, Water Air Soil Pollut., 115, 219-243, 1999.

Bossan, D., Wortham, H., and Masclet, P.: Atmospheric transport of pesticides adsorbed on aerosols. I. photodegradation in simulated atmosphere, Chemosphere, 30, 21-29, 1995.

Bunce, N., Liu, L., Zhu, J., and Lane, D.: Reaction of naphthalene and its derivatives with $\mathrm{OH}$ radicals in the gas phase, Environ. Sci. Technol., 31, 2252-2259, 1997.

Calvert, J. G., Atkinson, R., Becker, K. H., Kamens, R. M., Seinfeld, J. H., Wallington, T. J., and Yarwood, G.: The mechanisms of atmospheric oxidation of aromatic hydrocarbons, Oxford University Press, New York, 2002.

Carter, W. P. L., Luo, D., and Malkina, I. L.: Investigation of the atmospheric reactions of chloropicrin, Atmos. Environ., 31, 14251439, 1997.

Chevreuil, M., Garmouna, M., Teil, M. J., and Chesterikoff, A.: Occurence of organochlorines (PCBs, pesticides) and herbicides (triazines, phenylureas) in the atmosphere and in the fallout from urban and rural stations of Paris area, Sci. Total Environ., 182, 25-37, 1996.

Coupe, R. H., Manning, M. A., Foreman, W. T., Goolsby, D. A., and Majewski, M. S.: Occurrence of pesticides in rain and air in urban and agricultural areas of Mississippi, april-september 1995, Sci. Total Environ, 248, 227-240, 2000.

Daisey, J. M., Lewandowski, C. G., and Zorz, M.: A photoreactor for investigations of the degradation of particle-bound polycyclic aromatic hydrocarbons under simulated atmospheric conditions, Environ. Sci. Technol., 16, 857-861, 1982.

Donaldson, D. J. and Vaida, V.: The influence of organic films at the air-aqueous boundary on atmospheric processes, Chem. Rev., 106, 1445-1461, 2006.

Esteve, W., Budzinski, H., and Villenave, E.: Relative rate constants for the heterogeneous reactions of $\mathrm{OH}, \mathrm{NO}_{2}$ and $\mathrm{NO}$ radicals with polycyclic aromatic hydrocarbons adsorbed on carbonaceous particles, Part 1: PAHs adsorbed on 1-2 mm calibrated graphite particles, Atmos. Environ., 38, 6063-6072, 2004.

Esteve, W., Budzinski, H., and Villenave, E.: Relative rate constants for the heterogeneous reactions of $\mathrm{NO}_{2}$ and $\mathrm{OH}$ radicals with polycyclic aromatic hydrocarbons adsorbed on carbonaceous particles, Part 2: PAHs adsorbed on diesel particulate exhaust SRM 1650a, Atmos. Environ., 40, 201-211, 2006.
Finlayson-Pitts, B. J. and Pitts Jr., J. N.: Chemistry of the upper and lower atmosphere: theory, experiments and applications, Academic press, USA, 2000.

Fuller, E. N., Schettler, P. D., and Giddings, J. C.: A new method for prediction of binary gas-phase diffusion coefficients, Ind. Eng. Chem., 58, 18-27, 1966.

Gloaguen, E., Mysak, E. R., Leone, S. R., Ahmed, M., and Wilson, K. R.: Investigating the chemical composition of mixed organicinorganic particles by "soft" vacuum ultraviolet photoionization: The reaction of ozone with anthracene on sodium chloride particles, Int. J. Mass spectrom., 258, 74-85, 2006.

Goriaux, M.: Etude des artefacts de prélèvement et de la distribution gaz-particules des HAP, PhD thesis, Laboratoire Chimie et Environnement, Université de Provence Aix-Marseille I, France, 2006.

Goriaux, M., Jourdain, B., Wortham, H., Temime, B., Besombes, J. L., Marchand, N., Albinet, A., and Leoz-Garziandia, E.: Field comparison of particulate PAH measurements using a low-flow denudeur device and conventional sampling systems, Environ. Sci. Technol., 40, 6398-6404, 2006.

Gundel, L. A., Lee, V. C., Mahanama, K. R. R., Stevens, R. K., and Daisey, J. M.: Direct determination of the phase distributions of semi-volatile polycyclic aromatic hydrocarbons using annular denuders, Atmos. Environ., 29, 1719-1733, 1995.

Hung, H., Blanchard, P., Halsall, C. J., Bidleman, T. F., Stern, G. A., Fellin, P., Muir, D. C. G., Barrie, L. A., Jantunen, L. M., Helm, P. A., Ma, J., and Konoplev, A.: Temporal and spatial variabilities of atmopsheric polychlorinated biphenyls (PCBs), organochlorine (OC) pesticides and polycyclic aromatic hydrocarbons (PAHs) in the Canadian Artic: Results from a decade of monitoring, Sci. Total Environ., 342, 119-144, 2005.

Hunt, G. and Pangaro, N.: Potential contamination from the use of synthetic adsorbents in air sampling procedures, Anal. Chem., 54, 369-372, 1982.

Kahan, T. F., Kwamena, N. O. A., and Donaldson, D. J.: Heterogeneous ozonation kinetics of polycyclic aromatic hydrocarbons on organic films, Atmos. Environ., 40, 3448-3459, 2006.

Kwamena, N. O. A., Thornton, J. A., and Abbatt, J. P. D.: Kinetics of surface-bound Benzo[a]Pyrene and ozone on solid organic and salt aerosols, J. Phys. Chem. A., 108, 11626-11634, 2004.

Kwamena, N. O. A., Earp, M. E., Young, C. J., and Abbatt, J. P. D.: Kinetic and product yield study of the heterogeneous gas-surface reaction of anthracene and ozone, J. Phys. Chem. A., 110, 36383646, 2006.

Kwamena, N. O. A., Staikova, M. G., Donaldson, D. J., George, I. J., and Abbatt, J. P. D.: Role of the aerosol substrate in the heterogeneous ozonation reactions of surface-bound PAHs, J. Phys. Chem. A., 111, 11050-11058, 2007.

Kwok, E. S. and Atkinson, R.: Estimation of hydroxyl radical reaction rate constants for gas-phase organic compounds using a structure-reactivity relationship: an update, Atmos. Environ., 29, 1685-1695, 1995.

Le Person, A., Mellouki, A., Munoz, A., Borras, E., MartinReviejo, M., and Wirtz, K.: Trifluralin: Photolysis under sunlight conditions and reaction with $\mathrm{HO}$ radicals, Chemosphere, 67, 376-383, 2007.

Lei, Y. D., Chankalal, R., Chan, A., and Wania, F.: Supercooled liquid vapour pressures of the polycyclic aromatic hydrocarbons, J. Chem. Eng. Data, 47, 801-806, 2002. 
Michel, A. E., Usher, C. R., and Grassian, V. H.: Reactive uptake of ozone on mineral oxides and mineral dusts, Atmos. Environ., 37, 3201-3211, 2003.

Palm, W. U., Elend, M., Krueger, H. U., and Zetzsch, C.: OH radical reactivity of airborne terbutylazine adsorbed on inert aerosol, Environ. Sci. Technol., 31, 3389-3396, 1997.

Palm, W. U., Millet, M., and Zetzsch, C.: $\mathrm{OH}$ radical reactivity of pesticides adsorbed in aerosol materials: first results of experiments with filter samples, Ecotoxicol. Environ. Saf., 41, 36-43, 1998.

Palm, W. U., Elend, M., Krüger, H. U., and Zetzsch, C.: Atmospheric degradation of a semivolatile aerosol-borne pesticide: reaction of $\mathrm{OH}$ with pyrifenox (an oxime-ether), adsorbed on $\mathrm{SiO}_{2}$, Chemosphere, 38, 1241-1252, 1999.

Perraudin, E., Budzinski, H., and Villenave, E.: Kinetic study of the reactions of $\mathrm{NO} 2$ with polycyclic aromatic hydrocarbons adsorbed on silica particles, Atmos. Environ., 39, 6557-6567, 2005.

Perraudin, E., Budzinski, H., and Villenave, E.: Identification and quantification of ozonation products of anthracene and phenanthrene adsorbed on silica particles, Atmos. Environ., 41, 60056017, 2007a.

Perraudin, E., Budzinski, H., and Villenave, E.: Kinetic study of the reactions of ozone with polycyclic aromatic hydrocarbons adsorbed on atmospheric model particles, J. Atmos. Chem., 56, 57-82, $2007 b$.

Pöschl, U., Letzel, T., Schauer, C., and Niessner, R.: Interaction of ozone and water vapor with spark discharge soot aerosol particles coated with benzo[a]pyrene: $\mathrm{O} 3$ and $\mathrm{H} 2 \mathrm{O}$ adsorption, benzo[a]pyrene degradation, and atmospheric implications, J. Phys. Chem. A., 105, 4029-4041, 2001.

Possanzini, M., Febo, A., and Liberti, A.: New design of highperformance denuder for the sampling of atmospheric pollutants, Atmos. Environ., 17, 2605-2610, 1983.

Rudich, Y.: Laboratory perspectives on the chemical transformations of organic matter in atmospheric particles, Chem. Rev., 103, 5097-5124, 2003.
Rudich, Y., Donahue, N. M., and Mentel, T. F.: Aging of organic aerosol: bridging the gap between laboratory and field studies, Annu. Rev. Phys. Chem., 58, 321-352, 2007.

Sauret-Szczepanski, N., Mirabel, P., and Wortham, H.: Development of a SPME-GC-MS/MS method for the determination of pesticides in rain water, Environ. Pollut., 139, 133-142, 2006.

Scheyer, A., Graeff, C., Morville, S., Mirabel, P., and Millet, M.: Analysis of some organochlorine pesticides in an urban atmosphere (Strasbourg, east of France), Chemosphere, 58, 1517$1524,2005$.

Soderquist, C. J., Crosby, D. G., Moilanen, K. W., Seiber, J. N., and Woodrow, J. E.: Occurrence of trifluralin and its photoproducts in air, J. Agric. Food. Chem., 23, 304-309, 1975.

Tasdemir, Y. and Esen, F.: Urban air PAHs: Concentrations, temporal changes and gas/particle partitioning at a traffic site in Turkey, Atmos. Res., 84, 1-12, 2007.

Temime, B., François, S., Monod, A., and Wortham, H.: An experimental set up of a PAH vapour generator and its use to test an annular denuder, Environ. Pollut., 120, 609-616, 2002.

Temime, B., Monod, A., Massiani, C., and Wortham, H.: Evaluation of an annular denuder tubes for atmospheric PAH partitioning studies. 1. Evaluation of the trapping efficiency of gaseous PAH, Atmos. Environ., 38, 1913-1924, 2004.

Usher, C. R., Michel, A. E., Stec, D., and Grassian, V. H.: Laboratory studies of ozone uptake on processed mineral dust, Atmos. Environ., 37, 5337-5347, 2003a.

Usher, C. R., Michel, A. E., and Grassian, V. H.: Reactions on Mineral Dust, Chem. Rev., 103, 4883-4939, 2003b

Woodrow, J. E., Crosby, D. G., Mast, T., Moilanen, K. W., and Seiber, J. N.: Rates of transformation of trifluralin and parathion vapors in air, J. Agric. Food. Chem., 26, 1312-1316, 1978.

Wortham, H., Bon Nguyen, E., Masclet, P., and Mouvier, G.: Study of heterogenous reactions of polycyclic aromatic hydrocarbons I: weakening of PAH-support bonds under photonic irradiation, Sci. Total Environ., 128, 1-11, 1993.

Zielinska, B.: Atmospheric transformation of diesel emissions, Exp. Toxicol. Pathol., 57, 31-42, 2005. 